\title{
MOTIVAÇÕES PARA A INTERNACIONALIZAÇÃO E MODOS DE ENTRADA NOS MERCADOS EXTERNOS
}

\section{INTERNATIONALIZATION MOTIVATIONS AND FOREIGN MARKET ENTRY MODES}

\section{MOTIVACIONES PARA LA INTERNACIONALIZACIÓN Y MODOS DE ENTRADA EN LOS MERCADOS EXTERNOS}

\section{Manuel Aníbal Silva Portugal Vasconcelos Ferreira \\ Doutor em Gestão pela Universidade de Coimbra - UC \\ Professor do Instituto Politécnico de Leiria - IPL \\ E-mail: manuel.portugal.ferreira@gmail.com (Portugal)}

\section{Fernando Ribeiro Serra}

Doutor em Engenharia Materiais e de Processos Químicos e Metalúrgicos pela Pontifícia Universidade Católica do Rio de Janeiro - PUC/RJ

Professor da Universidade do Sul de Santa Catarina - UNISUL

E-mail: nuno.m.reis@estg.ipleiria.pt (Brasil)

\section{Nuno Manuel Rosa dos Reis}

Doutor em Gestão de Empresas pela Faculdade de Economia da Universidade de Coimbra - UC Assistente do Instituto Politécnico de Leiria - IPL

E-mail: nuno.m.reis@estg.ipleiria.pt (Portugal) 
Motivações para a Internacionalização e Modos de Entrada nos Mercados Externos

MOTIVAÇÕES PARA A INTERNACIONALIZAÇÃO E MODOS DE ENTRADA NOS MERCADOS EXTERNOS

\section{RESUMO}

As motivações para a internacionalização das empresas devem influenciar a seleção dos modos de entrada nos mercados externos. Neste artigo usamos a classificação de John Dunning (1993) que distingue quatro motivos - procura de mercado, de recursos, de eficiência e de recursos estratégicos - discutindo conceptualmente qual o impacto sobre os modos de entrada escolhidos. As formas e estratégias das empresas multinacionais (EMNs) são escolhidas num quadro alargado onde convergem motivações com a exploração ou prospecção de vantagens específicas à empresa. A nossa análise é suportada num conjunto de proposições teóricas. O resultado é que as EMNs precisam desenvolver a melhor combinação possível de estratégia-estrutura para as suas operações internacionais, mas fazendo uma análise casuística de cada operação individual. Contribuímos, assim, para compreender melhor a seleção dos modos de entrada como enquanto reflexo de opções ou motivações estratégicas.

Palavras-chave: Motivações para a Internacionalização; Procura de Recursos Estratégicos; Procura de Mercado; Modos de Entrada nos Mercados Externos; Seleção dos Mercados.

\section{INTERNATIONALIZATION MOTIVATIONS AND FOREIGN MARKET ENTRY MODES}

\section{ABSTRACT}

The motivations for the internationalization of firms influence the selection of foreign entry modes. In this article we use John Dunning's (1993) classification, which distinguishes four primary motives to invest overseas - market seeking, resource seeking, strategic asset seeking and efficiency seeking -, conceptually discussing the impact of the selected foreign entry modes. The methods and strategies of multinational corporations (MNCs) are chosen in a broader framework, where internationalization motivations converge with the exploitation, or exploration, of firm-specific advantages. Our analysis is supported by a set of theoretical propositions. The results demonstrate that MNCs must develop the best possible combination of strategy-structure for their international operations, and yet conceive a casuistic analysis of each individual operation. We have therefore contributed to a better understanding of the selection of foreign market entry modes as a reflection of strategic choices or motivations.

Keywords: Internationalization Motivations; Strategic Asset Seeking; Market Seeking; Foreign Market Entry Modes; Market Selection. 
Manuel Aníbal Silva Portugal Vasconcelos Ferreira, Fernando Ribeiro Serra \& Nuno Rosa Reis.

\section{MOTIVACIONES PARA LA INTERNACIONALIZACIÓN Y MODOS DE ENTRADA EN LOS MERCADOS EXTERNOS}

\section{RESUMEN}

Las motivaciones para la internacionalización de las empresas deben influir en la selección de los modos de entrada en los mercados externos. En este paper usamos la clasificación de John Dunning (1993) que distingue cuatro motivos - búsqueda de mercado, de recursos, de eficiencia y de recursos estratégicos - discutiendo conceptualmente cuál es el impacto sobre los modos de entrada escogidos. Las formas y estrategias de las empresas multinacionales (EMNs) son escogidas en un cuadro amplio donde convergen las motivaciones con la explotación o prospección de ventajas específicas a la empresa. Nuestro análisis es sostenido en un conjunto de proposiciones teóricas. El resultado es que las EMNs necesitan desarrollar la mejor combinación posible de estrategiaestructura para sus operaciones internacionales, pero haciendo un análisis casuístico de cada operación individual. Contribuimos, así, para comprender mejor la selección de los modos de entrada como reflejo de las opciones o motivaciones estratégicas.

Palabras-clave: Motivaciones para la Internacionalización; Búsqueda de Recursos Estratégicos; Busca de Mercado; Modos de Entrada en los Mercados Externos; Selección de los Mercados. 


\section{INTRODUÇÃO}

A investigação dos modos de entrada nos mercados externos e das formas e padrões de investimento direto estrangeiro (IDE) é extensa e abrange diferentes disciplinas, desde a gestão de empresas, às teorias do comércio internacional, inovação etc. No entanto, as motivações que realmente subjazem às estratégias de internacionalização das empresas e que resultam na realização de investimento carecem de pesquisa, nomeadamente enquanto fatores determinantes - e eventuais consequências - de operações de IDE. Uma exceção importante é o trabalho de Dunning (1977, 1988, 1993) que tem servido de inspiração à abordagem deste aspecto nos negócios internacionais.

A classificação das motivações proposta por Dunning (1993) assenta em quatro principais motivos para o IDE: procura de mercado (market seeking), procura de recursos (resource seeking), procura de eficiência (efficiency seeking) e procura de recursos estratégicos (strategic resource seeking). Ainda assim, as motivações apresentadas por Dunning estão fortemente vinculadas ao paradigma eclético (também reconhecido por OLI - Ownership, Location e Internalization) e são pouco explícitas como variáveis essenciais na escolha de estratégias alternativas - como é o caso da escolha dos modos de entrada nos mercados externos e, de certa forma, mesmo na seleção dos mercados (AGARWAL; RAMASWAMI, 1992). De facto, é possível que diferentes alternativas de atuação estratégica tenham subjacentes a mesma motivação. Por outro lado, sem ter em conta a motivação para cada operação individualmente, há o risco de assumir que as empresas multinacionais adotam sempre, e linearmente, a mesma estratégia.

As motivações para a internacionalização da empresa podem ter um impacto profundo sobre (a) o modo de entrada escolhido, (b) a seleção do país estrangeiro onde entrar, ou seja, a escolha da localização. Então, na escolha entre as alternativas, a decisão final não passa necessariamente pela realização de IDE, nem esta decisão é independente da seleção dos países onde operar. Neste contexto importa, nomeadamente, entender os mercados, ou países, onde localizar a produção. A localização é importante pelos fatores tradicionais de atratividade dos espaços, pelos custos de transação que podem estar envolvidos e porque certos locais são polos de forte atratividade para aceder a um recurso estratégico por excelência: o conhecimento.

Neste artigo, investigamos como diferentes motivações de internacionalização (por exemplo, a procura por mercados ou por recursos estratégicos) influenciam a seleção do modo de entrada preferido pelas empresas multinacionais (EMNs), com referências explícitas aos países escolhidos. Contribuímos, assim, para melhor entender as estratégias de entrada em mercados externos (seguindo FERREIRA; SERRA, 2008; FERREIRA; LI; JANG, 2009). O foco nas motivações, 
Manuel Aníbal Silva Portugal Vasconcelos Ferreira, Fernando Ribeiro Serra \& Nuno Rosa Reis.

usando a classificação de Dunning (1993) permite realçar o uso contrastante de ativos específicos pelas empresas. Tomamos, assim, a seleção do modo de entrada como uma ação estratégica (OLIVER, 1991; NIELSEN; NIELSEN, 2011), no quadro de uma avaliação interna da empresa nomeadamente dos seus próprios recursos estratégicos, que poderá alavancar ou que precisa desenvolver - e externa - da atratividade relativa dos territórios.

Este artigo é estruturado como segue. Primeiro, fazemos uma breve abordagem aos modos de entrada nos mercados externos. Na segunda parte, analisamos as motivações para a internacionalização das empresas. A formulação de proposições teóricas assenta no ajustamento dos modos de entrada face às motivações para a internacionalização. Esta análise integra, ainda, considerações sobre a seleção das localizações no estrangeiro. Concluímos com uma discussão abrangente da nossa análise, apontando implicações para a teoria e a prática e antecipando linhas de possível investigação futura.

\section{LITERATURA E PROPOSIÇÕES}

\subsection{AS ESTRATÉGIAS DE ENTRADA EM MERCADOS EXTERNOS}

A seleção dos modos de entrada nos mercados externos é uma das decisões mais complexas na internacionalização (AGARWAL; RAMASWAMI, 1992; MORSCHETT; SCHRAMM-KLEIN; SWOBODA, 2010). Embora não seja nosso objetivo fazer uma resenha da literatura dos modos de entrada, notamos que há três principais abordagens aos modos de entrada. Uma que assenta na escola evolucionista (por exemplo, LUOSTARINEN; WELCH, 1990; ROOT, 1994; JOHANSON; VAHLNE, 2009), que propõem um modelo em que os modos de entrada seguem um padrão sequencial que se inicia com a realização de exportações e evolui até ao investimento direto estrangeiro (IDE).

A segunda abordagem argumenta que a internacionalização das multinacionais (EMNs) é influenciada por mercados imperfeitos (veja-se RUGMAN, 1981; HENNART, 1982; WILLIAMSON, 1985; DUNNING, 1988; MAKINO; NEUPERT, 2000; BROUTHERS; HENNART, 2007), pelo que as imperfeições do mercado são encaradas na seleção dos modos de entrada. Em resumo, estipula que quanto maiores as imperfeições, maior a propensão a que as EMNs escolham modos como os investimentos de raiz (greenfield), aquisições ou joint-ventures (HENNART, 1982; ROOT, 1994; MAKINO; NEUPERT, 2000; BROUTHERS; HENNART, 2007).

Revista Ibero-Americana de Estratégia - RIAE, São Paulo, v. 10, n. 1, p. 29-54, jan/abr. 2011. 
Motivações para a Internacionalização e Modos de Entrada nos Mercados Externos

A terceira abordagem baseia-se nas redes relacionais e na ideia que os relacionamentos interempresas são fontes de informação de oportunidades e influenciam as opções estratégicas das empresas (JOHANSON; MATTSON, 1988; JOHANSON; VAHLNE, 2009). Em certos casos, estes relacionamentos podem significar uma redução das tradicionais desvantagens de ser estrangeiro (liability of foreignness), nomeadamente quando usa modos colaborativos como as joint-ventures (ZAHEER, 1995; ELANGO, 2009).

Podemos definir claramente seis modos de entrada distintos: exportações, licenciamento, joint ventures, alianças estratégicas, investimentos greenfield e aquisições. A adequação de cada um destes modos de entrada dependerá das motivações da empresa, quer a cada um dos negócios, quer a cada país onde se estabelece. Por exemplo, objetivos de envolvimento mais profundo e de longo prazo podem sustentar a decisão de realizar um investimento greenfield, enquanto objetivos de curto prazo recomendariam modos de menor envolvimento, como as exportações ou formas de licenciamento. Seria, também, razoável sugerir que objetivos de aprendizagem local poderiam ser melhor realizados com o estabelecimento de parcerias com empresas domésticas no destino.

As EMNs que operam num país anfitrião estão em desvantagem em relação às empresas locais (HYMER, 1976; ZAHEER, 1995; ELANGO, 2009). Tratam-se de desvantagens relacionadas com a falta de conhecimento do país anfitrião em dimensões como o ambiente político, questões legais, normas sociais, preferências dos consumidores, entre outros. Contudo, à medida que as empresas estrangeiras acumulam experiência e conhecimento sobre o mercado anfitrião, melhoram a sua capacidade para operar no país receptor (DUNNING, 1993; BARKEMA ET AL., 1996; FERREIRA, 2008; FERREIRA ET AL., 2011). Aliás, o grau de envolvimento e o modo de entrada nos mercados externos escolhido pelas EMNs dependem do conhecimento sobre o país anfitrião. Por exemplo, as empresas podem preferir iniciar as suas operações externas através de uma forma de parceria (por exemplo, joint venture ou aliança estratégica) ou através de modos com um menor compromisso (por exemplo, exportações ou licenciamento). Depois de adquirida experiência e conhecimento sobre o mercado anfitrião, as EMNs podem considerar vantajoso usar outros modos de operar, como os investimentos greenfield ou aquisições de empresas instaladas (MAKINO; NEUPERT, 2000; GAO; PAN, 2010).

\subsection{MOTIVAÇÕES PARA A INTERNACIONALIZAÇÃO}

A análise das estratégias de internacionalização deve contemplar o entendimento e porque é que umas vezes as empresas realizam investimentos greenfield, outras aquisições, joint ventures, preferem mecanismos contratuais como o licenciamento, ou simplesmente restringir-se à

Revista Ibero-Americana de Estratégia - RIAE, São Paulo, v. 10, n. 1, p. 29-54, jan/abr. 2011. 
Manuel Aníbal Silva Portugal Vasconcelos Ferreira, Fernando Ribeiro Serra \& Nuno Rosa Reis.

exportação para um mercado receptor. Genericamente, a decisão envolve, pelo menos, duas etapas. Primeiro, a detecção de uma oportunidade no estrangeiro, que se pode materializar numa decisão de localização. Segundo, a seleção entre modos alternativos de atuar para explorar essa oportunidade. É razoável sugerir que o modo de explorar a oportunidade depende do tipo de oportunidade em questão. Por exemplo, se a oportunidade for o mercado externo, então várias alternativas poderão ser razoavelmente ponderadas: exportação, IDE e licenciamento permitem captar parte do mercado. Se, por outro lado, a oportunidade residir nos baixos custos salariais no estrangeiro, a subcontratação a empresas locais ou o IDE serão as melhores opções. Ou seja, os motivos moldam a forma como a empresa atua - nomeadamente os modos de entrada. Também o tipo de oportunidade fará variar a localização escolhida, pelo que o modo e o local não são decisões completamente independentes.

A classificação das motivações para a internacionalização (ainda que comumente referida como motivações para o IDE) mais conhecida é a proposta por Dunning (1977, 1993, 2001) construída sobre o paradigma eclético. Efetivamente, as motivações não sustentam apenas operações de investimento, mas sim, mais genericamente, de modos de entrada. Esta classificação distingue quatro tipos de motivações, como segue:

a) Procura de recursos (resource seeking) - neste motivo a empresa procura aceder a recursos que não estão disponíveis no seu mercado doméstico, como, por exemplo, recursos naturais, matérias-primas, ou que estão disponíveis a mais alto custo, como mão de obra comparativamente mais cara. O objetivo tradicional nestes casos é localizar pelo menos parte da cadeia de valor no estrangeiro como forma de beneficiar de custos mais baixos dos fatores de produção.

b) Procura de mercado (market seeking) - as empresas investem para capturar mercado (consumidores). Nas teorias mais clássicas do comércio internacional, por exemplo, este motivo pode ser enquadrado na tentativa de evitar custos de transporte - e neste caso a empresa seleciona o IDE em alternativa a, por exemplo, exportações (MARKUSEN; VENABLES, 2000; BUCKLEY ET AL., 2008).

c) Procura de eficiência (efficiency seeking) - quando este motivo vigora, a empresa realiza IDE se consegue beneficiar de diferenças entre países quanto ao custo ou disponibilidade dos fatores de produção e consegue beneficiar de economias de escala, gama e diferenças nos gostos dos consumidores. Este motivo pode ser tido 
Motivações para a Internacionalização e Modos de Entrada nos Mercados Externos

como idêntico ao de procura de recursos na medida em que a empresa divide a produção de modo a beneficiar de, por exemplo, custos mais baixos da mão de obra em países menos desenvolvidos.

d) Os três motivos anteriores assentam na ideia que a empresa se internacionaliza, eventualmente realizando IDE, porque pode realizar lucros adicionais ao explorar ativos específicos, tais como recursos tecnológicos que são transferidos para as subsidiárias no estrangeiro (CANTWELL, 1989; BUCKLEY ET AL., 2008).

e) Procura de recursos estratégicos (strategic asset seeking) - as empresas realizam IDE com vista a adquirir novas competências e recursos, ou capacidades dinâmicas, em vez de se limitarem a explorar os ativos de que já dispõem (ver, também, FERREIRA, 2005; FERREIRA; LI; LOPES; SERRA, 2007; LI; FERREIRA; SERRA, 2009). Neste motivo não há intenção de explorar vantagens competitivas prévias, mas antes desenvolver novas vantagens. Ao realizar IDE, a empresa consegue aceder a conhecimento específico a localizações (países, regiões ou mesmo cidades) receptoras ao aí sedear subsidiárias.

A tabela 1, seguinte, sintetiza as motivações, objetivos, modos de entrada e localização.

Tabela 1 - Motivos para a internacionalização, modos e localização: Uma análise conjunta

\begin{tabular}{|c|c|c|c|c|}
\hline MOTIVO & PROPÓSITO & $\begin{array}{c}\text { ALTERNATIVAS } \\
\text { AO IDE }\end{array}$ & $\begin{array}{l}\text { DETERMINANTES } \\
\text { DA } \\
\text { INTERNALIZAÇÃO }\end{array}$ & $\begin{array}{c}\text { DETERMINANTES } \\
\text { DA } \\
\text { LOCALIZAÇÃO } \\
\end{array}$ \\
\hline $\begin{array}{l}\text { Procura de } \\
\text { mercado }\end{array}$ & $\begin{array}{l}\text { Explorar o potencial } \\
\text { de comercialização } \\
\text { num Mercado mais } \\
\text { alargado no país } \\
\text { receptor ou na região } \\
\text { envolvente }\end{array}$ & $\begin{array}{l}\text { Licenciamento e } \\
\text { exportação }\end{array}$ & $\begin{array}{c}\text { Barreiras } \\
\text { governamentais (+), } \\
\text { custos de transporte } \\
(+), \text { facilidade de } \\
\text { imitação (-), facilidade } \\
\text { de proteger com } \\
\text { patente (varia) }\end{array}$ & $\begin{array}{l}\text { Dimensão do mercado } \\
\text { receptor }(+), \text { taxa de } \\
\text { crescimento do } \\
\text { Mercado receptor }(+), \\
\text { pode ser uma } \\
\text { plataforma para a } \\
\text { exportação }(+), \\
\text { diferenças no custo do } \\
\text { trabalho }(+)\end{array}$ \\
\hline $\begin{array}{l}\text { Procura de } \\
\text { recursos }\end{array}$ & $\begin{array}{l}\text { Aceder a certos } \\
\text { recursos } \\
\text { (genericamente } \\
\text { definidos como a } \\
\text { dotação natural do } \\
\text { país) }\end{array}$ & $\begin{array}{l}\text { Subcontratação } \\
\text { internacional e } \\
\text { comércio } \\
\text { internacional }\end{array}$ & $\begin{array}{l}\text { Especificidade dos } \\
\text { recursos (+), incerteza } \\
(+), \text { intangibilidade } \\
\text { dos recursos (+), } \\
\text { Complementaridade } \\
\text { dos recursos (+) }\end{array}$ & $\begin{array}{l}\text { Custo do recurso (-), } \\
\text { Escassez do recurso } \\
(+), \text { produtividade } \\
\text { relativa do recurso }(+)\end{array}$ \\
\hline
\end{tabular}

Revista Ibero-Americana de Estratégia - RIAE, São Paulo, v. 10, n. 1, p. 29-54, jan/abr. 2011. 
Manuel Aníbal Silva Portugal Vasconcelos Ferreira, Fernando Ribeiro Serra \& Nuno Rosa Reis.

\begin{tabular}{|c|c|c|c|c|}
\hline $\begin{array}{l}\text { Procura de } \\
\text { recursos } \\
\text { estratégicos }\end{array}$ & $\begin{array}{l}\text { Absorver recursos a } \\
\text { cujo acesso só é } \\
\text { possível em } \\
\text { proximidade e que } \\
\text { não são passíveis de } \\
\text { ser transferidos } \\
\text { através de } \\
\text { mecanismos de } \\
\text { mercado }\end{array}$ & $\begin{array}{l}\text { Alianças estratégicas } \\
\text { e joint ventures, } \\
\text { aquisição de } \\
\text { empresas instaladas, } \\
\text { contratação local de } \\
\text { trabalhadores }\end{array}$ & $\begin{array}{l}\text { Grau de rivalidade no } \\
\text { mercado }(+) \text {, grau de } \\
\text { transferabilidade do } \\
\text { conhecimento pelo } \\
\text { contacto directo com } \\
\text { parceiro (-), } \\
\text { competências da } \\
\text { empresa (+) }\end{array}$ & $\begin{array}{l}\text { Infra-estrutura básica } \\
\text { e avançada (+), } \\
\text { Distância tecnológica } \\
\text { entre o país de origem } \\
\text { e o de destino }(+)\end{array}$ \\
\hline
\end{tabular}

Fonte: Adaptado de FRANCO; RENTOCCHINI; MARZETTI, 2008.

\subsection{PROCURA DE RECURSOS NO ESTRANGEIRO}

Um dos motivos para as empresas se internacionalizarem é a procura de recursos. De acordo com Dunning $(1993,1998)$, incluímos aqui os casos em que as empresas pretendem aceder a um recurso específico que não está disponível no mercado doméstico (por exemplo, um recurso natural) ou que é possível obter a um custo mais baixo num país estrangeiro (por exemplo, mão de obra mais barata). Em essência, estes recursos referem-se a recursos naturais e trabalho não qualificado, mas podem ser conceptualizados para incluir fatores mais sofisticados, como sejam as competências tecnológicas e de gestão. Poderemos, também, distinguir as competências tecnológicas e de gestão, dado que estes recursos apenas atraem IDE se não forem passíveis de transação no mercado (FRANCO; RENTOCCHINI; MARZETTI, 2008).

Em termos simples, na medida em que o acesso a estes recursos exige presença local, é relativamente evidente que obriga a investimentos locais. Importa notar, porém, que se existirem empresas locais eficientes e o mercado local for eficiente, a EMN pode ter acesso aos recursos naturais a um preço competitivo. Neste caso, em que os mercados locais são eficientes, a racionalidade para a internalização das transações pode não se verificar (ver a este propósito, Rugman (1981), Hennart (1982) e Williamson (1985) sobre os custos de transação). Num contexto de mercados locais eficientes, mesmo a opção por aquisição de uma empresa já instalada pode ser pouco viável. Por outro lado, caso os mercados não sejam eficientes, poderá haver formas de protecionismo, as empresas a operar serem detidas pelo Estado, ou simplesmente serem elas próprias ineficientes.

Proposição 1. As multinacionais terão uma preferência por investimentos greenfield, quando o motivo é procurar recursos. 
Motivações para a Internacionalização e Modos de Entrada nos Mercados Externos

Proposição 2. Mercados locais eficientes retiram o incentivo das multinacionais realizarem investimentos greenfield ou aquisições, quando o motivo é procurar recursos.

Ainda que pudesse ser razoável incluir o trabalho qualificado dentro da classificação de "procura de recursos estratégicos", Zanfei (2000) incluiu este fator na motivação de procura de recursos. O fato é que as competências dos trabalhadores, mesmo os qualificados, podem ser acedidas através de contratos - por exemplo, contratos de trabalho, de prestação de serviços etc. tornando-o um recurso idêntico aos outros. As alternativas, quer de localização, quer de modo de entrada para aceder a trabalho qualificado podem, portanto, ser analisadas tal como para qualquer outro recurso que seja transacionável.

Importa aqui estender a análise às fronteiras da firma e, em última análise, à decisão de fazer ou comprar (make or buy). Em todo o momento as EMNs estabelecem quais são as fronteiras da sua atividade para determinar se estendem as suas operações através de investimento estrangeiro ou se, pelo contrário, recorrem ao comércio ou à subcontratação (FERREIRA; SERRA, 2010). Tal como estipulado pela teoria dos custos de transação, haverá uma relação inversa entre a especificidade dos ativos e o recurso à subcontratação. Não fica, porém, excluída a análise de saber se a forma mais eficiente de explorar um determinado recurso é internamente ou através de relações com parceiros. Outros aspectos a ter em conta, prendem-se com a importância estratégica de efetivamente controlar a fonte dos recursos, da complementaridade dos recursos acedidos e da sua importância estratégica para a EMN, bem como outros custos de transação, como sejam os impostos aduaneiros, custos de transporte, dificuldades de coordenação das operações internacionais, etc.

Proposição 3. Baixos custos de transação retiram o incentivo das multinacionais realizarem investimentos greenfield ou aquisições, quando o motivo é procurar recursos.

\subsection{PROCURA DE MERCADO NO ESTRANGEIRO}

Um motivo para as EMNs se internacionalizarem e, eventualmente realizarem IDE, é classificado como procura de mercado (ou market seeking). Este é, aliás, um motivo recorrente na literatura, indicando que as EMNs procuram explorar um mercado estrangeiro receptor, ou mercados adjacentes, fornecendo-lhe produtos e serviços (MAKINO; LAU; YEH, 2002; BUCKLEY ET AL., 2008). Esta é uma primeira questão, na análise da motivação - com este tipo de motivação, o mercado a explorar não é necessariamente aquele onde o investimento é realizado. De notar que no caso de um país de destino ser apenas uma plataforma comercial para um mercado

Revista Ibero-Americana de Estratégia - RIAE, São Paulo, v. 10, n. 1, p. 29-54, jan/abr. 2011. 
Manuel Aníbal Silva Portugal Vasconcelos Ferreira, Fernando Ribeiro Serra \& Nuno Rosa Reis.

mais alargado, a empresa fará exportação a partir deste (MARKUSEN; VENABLES, 1998, 2000). Esta solução é mais viável quando a própria produção é instalada localmente ou quando os países vizinhos a serem servidos integram uma zona de comércio livre (EKHOLM; FORSLID; MARKUSEN, 2007).

A internacionalização motivada pela procura de mercados visa explorar vantagens específicas à empresa que, assim, comercializará no estrangeiro, produtos e serviços onde tem uma vantagem competitiva, nomeadamente face às empresas domésticas no país receptor (MAKINO ET AL., 2002; BUCKLEY ET AL., 2008). No entanto, importa observar, quer as características dos mercados receptores - que se forem fechados podem inviabilizar o serviço através de exportações quer as características dos próprios produtos - para verificar se são internacionalmente transacionáveis.

As exportações impõem menores custos fixos e menor risco que o IDE. Ainda assim, as barreiras burocráticas e tarifárias e os custos de transporte (face à natureza do produto) podem inviabilizar as exportações, absorvendo o diferencial de vantagem da EMN estrangeira face aos concorrentes locais (HYMER, 1976). O investimento em operações locais seria a alternativa mais razoável, mas apenas se, quer a dimensão do mercado, quer o seu potencial de crescimento e a importância estratégica de aí ter operações, o justificarem. Há outras alternativas, como seja o licenciamento a uma empresa local, mas esta opção exige que o ambiente institucional no país receptor proteja quer as vantagens proprietárias, quer os fluxos de rendimento (ou seja, que o licenciado pague efetivamente, cumprindo o contrato de licenciamento).

Em suma, é evidente que num argumento clássico a procura de mercado pode ser satisfeita através de exportação e de licenciamento, as características da localização e do produto podem justificar a escolha por modos que realizam a internalização das operações através do IDE. O IDE pode ser realizado se for a melhor forma de aproveitar as oportunidades de mercado num país estrangeiro. No entanto, a motivação da internacionalização deve distinguir se o objetivo é servir um mercado nacional apenas ou servir os países vizinhos - funcionando neste ultimo caso como plataforma comercial (EKHOLM; FORSLID; MARKUSEN, 2007). Se no primeiro caso, os fatores específicos ao país são os fundamentais, como sejam a dimensão do mercado, potencial de crescimento, perfil de rendimentos dos consumidores, etc. No segundo caso, é preciso fazer uma análise que inclui aspectos como os sentimentos patrióticos, as relações bilaterais, tarifas aduaneiras, etc. - ou seja, aspectos que elevam os custos de transação.

Revista Ibero-Americana de Estratégia - RIAE, São Paulo, v. 10, n. 1, p. 29-54, jan/abr. 2011. 
Motivações para a Internacionalização e Modos de Entrada nos Mercados Externos

Proposição 4. As multinacionais terão uma preferência por exportação ou licenciamento, quando o motivo é procurar mercado.

Proposição 5. As multinacionais terão uma preferência por investimento estrangeiro em localizações que servem como plataformas regionais, quando o motivo é procurar mercado.

Proposição 6. Baixos custos de transação aumentam o incentivo das multinacionais realizarem investimentos greenfield ou aquisições, quando o motivo é procurar mercado, em desfavor da exportação ou licenciamento.

\subsection{PROCURA DE EFICIÊNCIA NO ESTRANGEIRO}

O motivo de procura de eficiência resulta de uma tentativa de as EMNs tirarem partido das diferenças na disponibilidade e custos da dotação dos fatores de produção tradicionais em diferentes países, ou de explorar economias de escala e de gama e das diferenças nos gostos e preferências dos consumidores (Dunning, 1993). Pelo menos em parte, esta categoria de motivação é passível de ser incluída na procura de recursos, dado que pode ser vista como uma forma de dividir a cadeia de valor e beneficiar de custos do trabalho mais baixos nos países menos desenvolvidos (ver, por exemplo, ECKEL, 2003; NACHUM; ZAHEER, 2005).

A procura de maior eficiência assenta na exploração de recursos que a empresa já detém (ECKEL, 2003). Possivelmente, estes recursos específicos são desenvolvidos centralmente e transferidos para as subsidiárias para aplicação nos mercados locais onde operam (CANTWELL, 1989; NARULA; MARIN, 2005). As EMNs realizam investimento estrangeiro para aceder a recursos complementares e a vantagens competitivas associadas com uma localização ou com as empresas aí situadas. O resultado é que certas localizações também passam a incluir um leque mais alargado de atividades de valor acrescentado, como reflexo das vantagens de localização (FRANCO; RENTOCCHINI; MARZETTI, 2008). Então, muito do investimento, nomeadamente em países como os EUA, realizado por EMNs visa procurar eficiências sustentando o alargamento do leque de atividades de valor acrescentado nesses países.

Proposição 7. As multinacionais terão uma preferência por investimentos greenfield e aquisições, quando o motivo é procurar aumento da eficiência.

Revista Ibero-Americana de Estratégia - RIAE, São Paulo, v. 10, n. 1, p. 29-54, jan/abr. 2011. 
Manuel Aníbal Silva Portugal Vasconcelos Ferreira, Fernando Ribeiro Serra \& Nuno Rosa Reis.

\subsection{PROCURA DE RECURSOS ESTRATÉGICOS NOS MERCADOS EXTERNOS}

A linha clássica de investigação em internacionalização e de explicação para os fluxos e padrões de IDE foca os spillovers de conhecimento das empresas estrangeiras para as empresas domésticas, não os potenciais fluxos de conhecimento das empresas domésticas para as estrangeiras. Esta é a perspectiva tradicional em negócios internacionais, em que as empresas se internacionalizam para explorar as suas competências específicas nos mercados externos (HYMER, 1976; CAVES, 1971; DUNNING, 1993; MAKINO ET AL., 2002; FERREIRA, 2008).

Nas últimas duas décadas emergiu uma nova perspectiva na investigação em negócios internacionais salientando a importância de conquistar e aumentar as capabilities das empresas (DUNNING, 1993; BARKEMA; BELL; PENNINGS, 1996; AUGIER; TEECE, 2007). Barney (1991) e Conner e Prahalad (1996) referem-se como a perspectiva baseada no conhecimento ou nas competências, enquanto Tallman e Fladmoe-Lindquist (2002) designam-na por pesquisa baseada em capabilities. A ideia central é que as empresas podem expandir internacionalmente não apenas com o objetivo de explorar as suas capabilities e manter uma vantagem competitiva - como estabelece a linha mais tradicional em negócios internacionais - mas também para aumentar essas capabilities (MARCH, 1991; TALLMAN; FLADMOE-LINDQUIST, 2002; FERREIRA, 2008). Neste artigo, na sequência de Dunning (1993) referimo-nos-lhe como a procura de recursos estratégicos. A motivação de procura de recursos estratégicos afasta-se das abordagens tradicionais ao assumir que as empresas estrangeiras se internacionalizam não baseadas em algum tipo de vantagem específica que exploram no estrangeiro.

O objetivo da estratégia de procura de recursos estratégicos é aprender com outras empresas e em países diferentes (FERREIRA, 2005; FERREIRA; SERRA, 2008). Estes recursos procurados podem ser de diferentes tipos passíveis de serem genericamente caracterizados como competências em inovação, capabilities organizacionais, capacidade de penetração nos mercados, capacidade de acesso a canais de distribuição e competências na compreensão dos gostos e preferências dos consumidores (DUNNING, 1993). Estabelece-se, assim, que as empresas estrangeiras também podem aprender localmente, quer com as empresas domésticas, quer absorvendo o conhecimento mais geral que "está no ar" (MARSHALL, 1920).

É razoável sugerir que pelo menos a generalidade dos recursos estratégicos não são efetivamente transacionáveis, pelo menos internacionalmente, sendo acessíveis apenas a empresas que se localizam na sua proximidade (HEAD; RIES; SWENSON, 1995; DUNNING, 1998; MAKINO ET AL., 2002; TALLMAN ET AL, 2004). Ou seja, estes recursos não são passíveis de

Revista Ibero-Americana de Estratégia - RIAE, São Paulo, v. 10, n. 1, p. 29-54, jan/abr. 2011. 
Motivações para a Internacionalização e Modos de Entrada nos Mercados Externos

transação pela via usual dos mercados e exigem às empresas que se localizem nos países, ou regiões, para lhes aceder no contexto em que foram criados. As empresas precisam, nestes casos, de realizar IDE no país receptor.

Alguns dos recursos não transacionáveis estão caracterizados na literatura sobre clusters industriais, ou aglomerações, e podemos referir-lhes como sendo as externalidades das economias de aglomeração (MARKUSEN, 1996; PORTER, 2000; MASKELL, 2001; TALLMAN ET AL, 2004). A decisão de investir fica determinada e a escolha específica da localização mesmo dentro do país procurará, previsivelmente, a proximidade a outras firmas numa dada região. Estas localizações facilitam o acesso a fornecedores, clientes, trabalhadores qualificados, instituições direcionadas e, fundamentalmente, aos spillovers tecnológicos e de conhecimento que podem emergir (MARSHALL, 1920; HEAD ET AL., 1995; CAMISON; FORES, 2011). Nos estudos de geografia económica o papel dos clusters industriais está bem explicado (ver, por exemplo, os trabalhos de Krugman (1991), Fujita e outros (2001) e Tallman e outros (2004), entre outros).

Importa referir que certos recursos são particularmente específicos e pouco móveis, estando imbuídos na própria empresa, na sua cultura organizacional, métodos de trabalho e de gestão. São recursos que nem são facilmente comunicáveis, nem transferíveis pelo mercado (ZANDER; KOGUT, 1995; LI; FERREIRA; SERRA, 2009). São recursos indivisíveis do todo da firma. Noutros casos, são competências locais que foram desenvolvidas ao longo de uma história e não são replicáveis em outros locais, e muito menos através de fronteiras nacionais. Em suma, o acesso e absorção de certos recursos que não são transacionáveis exige a realização de investimento no local, no estrangeiro. A questão reside em: como lhes aceder? Ou seja, qual o melhor modo de entrada no mercado externo para beneficiar destes recursos estratégicos.

Uma das questões essenciais reside em saber como é que a empresa investidora estrangeira consegue melhor apropriar-se desse recurso estratégico - que podemos simplificar usando a concepção de conhecimento - e transferi-lo internamente entre a sua rede de subsidiárias (BARKEMA; VERMEULEN, 1998; FERREIRA, 2005; FERREIRA ET AL., 2007) sem perdas significativas de valor. Ou seja, qual o melhor modo de entrada. É razoável sugerir dois modos alternativos. As aquisições de empresas instaladas localmente na medida em que garantem o acesso a recursos específicos à empresa e à tomada de uma posição num mercado (FERREIRA, 2005). A aquisição de uma empresa instalada permite aceder aos trabalhadores que detém o conhecimento. Em muitos casos, porventura na maioria, os conhecimentos não são acessíveis apenas contratando trabalhadores-chave e é mesmo necessário adquirir toda uma empresa. As JVs permitem aceder e absorver os conhecimentos dos parceiros, na medida em que promovem a colaboração tecnológica.

Revista Ibero-Americana de Estratégia - RIAE, São Paulo, v. 10, n. 1, p. 29-54, jan/abr. 2011. 
Manuel Aníbal Silva Portugal Vasconcelos Ferreira, Fernando Ribeiro Serra \& Nuno Rosa Reis.

Proposição 8. As multinacionais terão uma preferência por aquisição ou joint ventures, quando o motivo é procurar recursos estratégicos.

Importa, porém notar que estas decisões - modo e mercado - não são tomadas em isolamento. Por exemplo, é menos provável a opção por um JV quando o nível de rivalidade no mercado é alto. Quando a rivalidade é alta é mais difícil fazer uma parceria com outra empresa a atuar no mesmo setor, dado que esta, previsivelmente, não quererá transmitir os seus conhecimentos a um competidor. Por outro lado, importa analisar os recursos que as EMNs já detêm e os que pretendem aceder. Por exemplo, aparentemente, as aquisições de empresas domésticas permitem um acesso mais rápido ao conhecimento local, apesar de eventuais dificuldades de absorção desse conhecimento devido a dificuldades de integração da empresa adquirida (FERREIRA, 2005; LI ET AL., 2009).

\subsection{O AMBIENTE DO PAÍS RECEPTOR: INTERNACIONALIZAÇÃO A MONTANTE E A JUSANTE}

Vários estudos já focaram como as empresas investem no estrangeiro para adquirir competências tecnológicas e conhecimentos. Este será o efeito estereótipo quando, por exemplo, empresas de países menos desenvolvidos investem em países mais desenvolvidos. Pradhan e Abraham (2005) notaram como em $80 \%$ dos casos as empresas indianas fazem aquisições nos países desenvolvidos com o objetivo quer de aceder aos mercados, quer de aceder a conhecimento específico às empresas adquiridas (em especial a aspectos como o nome de marca, tecnologias, redes de marketing e distribuição e conhecimento do negócio). Makino, Lau e Yeh (2002) notaram que as empresas taiwanesas também investem nos países mais desenvolvidos quando procuram elevar as suas competências e aceder a mercados e, em países menos desenvolvidos, para beneficiar de custos mais baixos do trabalho.

Empresas em regiões menos inovadoras e com um leque mais estreito de competências e conhecimento precisam melhorar a sua capacidade competitiva, o que podem fazer procurando recursos estratégicos no estrangeiro e/ou com outras empresas. O IDE também é uma forma de a empresa estrangeira captar eventuais externalidades no país receptor - nomeadamente quando visa o conhecimento em clusters industriais de excelência (FUJITA ET AL., 2001; TALLMAN ET AL., 2004). Estes investimentos permitem não apenas o acesso a conhecimentos e inovações, como também aumentar a visibilidade e reputação da empresa e aprender sobre os mercados consumidores (DENG, 2007).

Revista Ibero-Americana de Estratégia - RIAE, São Paulo, v. 10, n. 1, p. 29-54, jan/abr. 2011. 
Motivações para a Internacionalização e Modos de Entrada nos Mercados Externos

Assim, as empresas podem preferir enveredar por uma estratégia de aquisições de empresas já existentes para mais rapidamente expandir a sua base de conhecimentos (GUPTA; ROSS, 2001). $\mathrm{Na}$ realidade, estas empresas preferirão, nestes casos, investir em países desenvolvidos, onde encontram maior dotação de conhecimentos, tecnologias e competências de gestão (DUNNING, 1998). O fato é que, dita a teoria, que as aquisições são uma forma mais rápida de aceder e desenvolver competências do que a construção interna (nomeadamente através dos investimentos em IeD) (FERREIRA, 2005; DENG, 2007). Estas empresas podem, assim, integrar os recursos estratégicos da empresa adquirida - tais como capacidade de desenvolvimento de novos produtos, conhecimentos de marketing e de gestão, tecnologias de processo e de produto etc.

Por outro lado, as EMNs que procuram recursos estratégicos precisam desenvolver processos que lhes permitam um melhor entrosamento com o meio local. Este entrosamento facilitará, em princípio, a obtenção de conhecimento (ou seja, a aprendizagem) que as EMNs procuram (BARKEMA ET AL., 1996; JOHANSON; VAHLNE, 2009). Assim, ao respeitar e adotar as normas e práticas do país anfitrião as EMNs serão tidas por semelhantes a empresas locais e terão acesso facilitado a conhecimento local e outros recursos estratégicos específicos a cada país (PORTER, 1990, 2000; TALLMAN ET AL., 2004). Esta é a lógica que parece justificar o atual crescimento de alianças estratégicas e outras formas de parcerias, como as joint ventures, nos países ocidentais (DUNNING, 1993; BROUTHERS; HENNART, 2007).

Proposição 9. As multinacionais terão uma preferência por aquisição joint ventures na entrada em países mais desenvolvidos, quando o motivo é procurar recursos estratégicos, em vez de investimentos greenfield e exportações.

As motivações das EMNs são conjugadas com as características do país na determinação do melhor modo de entrada. Por exemplo, segundo Cantwell (2001) maiores distâncias institucionais entre países, evidenciam diferentes evoluções tecnológicas, pelo que previsivelmente os países terão diferentes dotações tecnológicas. As diferenças levarão as EMNs a tentar absorver o conhecimento de uma forma que confira um elevado grau de conformidade e entrosamento local, para melhor aceder aos recursos estratégicos locais. Assim, enquanto para uma estratégia de procura de mercado pode ser aconselhável um modo de entrada de baixo envolvimento (veja-se DUNNING, 1993), numa estratégia de procura de recursos estratégicos poderá ser preferível um modo de entrada de elevado compromisso (PING, 2009).

O ambiente de negócio de países menos desenvolvidos comporta maior risco de operação (HILL; HWANG; KIM, 1990; PING, 2009). Dada a ineficácia das instituições e os maiores riscos 
Manuel Aníbal Silva Portugal Vasconcelos Ferreira, Fernando Ribeiro Serra \& Nuno Rosa Reis.

de transação, nomeadamente pela dificuldade de garantir a realização dos termos contratuais, importa ajustar o modo de entrada no sentido do menor envolvimento. Por exemplo, em países menos desenvolvidos, gerir uma aliança, uma joint venture ou até uma aquisição parcial pode ser mais difícil que em países mais desenvolvidos (BEAMISH, 1985; DEMIRBAG; TATOGLU; GLAISTER, 2008).

As características do país receptor influenciam a escolha do modo de entrada. Por exemplo, os países desenvolvidos tendem a ter ambientes institucionais mais desenvolvidos (CUERVOCAZURRA; GENC, 2008; FERREIRA ET AL., 2009) e as instituições nos países desenvolvidos oferecem melhores garantias sobre a execução dos contratos, reduzindo os custos e riscos de transação e os comportamentos oportunistas (WILLIAMSON, 1985). Em contraste, nos países menos desenvolvidos os sistemas de informação são menos fiáveis e as instituições ineficazes dificultam a execução de contratos (DEMIRBAG ET AL, 2008), aumentando os custos de transação e a incerteza. Ou seja, riscos como os de apropriação indevida das rendas de inovação, de reverse engineering, cópia ilegal de software ou outras formas de propriedade intelectual são menores em países mais desenvolvidos. O contraste é evidente na medida em que, de modo geral, as oportunidades que os países desenvolvidos oferecem podem ser aproveitadas através da alavancagem das capabilites das EMNs no país anfitrião. Consequentemente, EMNs que seguem uma estratégia de procura de mercados podem servir estes países através de exportações. Também a melhor execução dos contratos garante que os acordos de licenciamento sejam cumpridos, evitando disputas legais.

Proposição 10. Altos custos de transação de operar em países menos desenvolvidos retiram o incentivo de a multinacional realizar investimentos greenfield, aquisições ou joint ventures, em favor da exportação, independentemente da motivação original.

\section{DISCUSSÃO E NOTAS FINAIS}

As motivações estratégicas, que neste artigo suportamos na distinção em quatro tipos procura por recursos, por mercados, por eficiência e por recursos estratégicos -são importantes na escolha do modo de entrada no estrangeiro. Importa, porém, compreender como características, quer da natureza do produto, quer as específicas às transações em cada território podem influenciar, ou moderar, a escolha dos modos de entrada. Referimos, em particular, os custos de transação de operar em certos mercados.

Revista Ibero-Americana de Estratégia - RIAE, São Paulo, v. 10, n. 1, p. 29-54, jan/abr. 2011. 
Motivações para a Internacionalização e Modos de Entrada nos Mercados Externos

Podemos distinguir simplificadamente, duas formas de atuação profundamente distintas. Por um lado, a exploração e alavancagem dos recursos, conhecimentos e capabilities detidos pela empresa, por outro, a procura de recursos estratégicos para adquirir novos recursos e conhecimentos, tecnologias, inovações, processos de negócio e outros, que contribuem para aumentar a capacidade competitiva. Assim, as empresas multinacionais realizam operações internacionais de procura de mercados para conquistar clientes em mercados externos. Mas, podem definir como prioridade para uma dada operação, num dado território, a procura de recursos estratégicos. É neste contexto que o modo de entrada precisa ser ajustado de forma a garantir que os objetivos serão concretizados.

Resumindo, ao passo que a perspectiva tradicional em negócios internacionais propõe que o objetivo das operações externas das EMNs é o aproveitamento de vantagens de propriedade existentes (DUNNING, 1993), perspectivas mais atuais complementam este objetivo com a proteção de uma vantagem competitiva existente ou o desenvolvimento de novas capabilites e vantagens competitivas.

Este artigo contribui para a investigação sobre a internacionalização das empresas, em particular sobre os modos de entrada e sobre as motivações em vários aspectos. A distinção clara das motivações de internacionalização permite estabelecer um quadro de referência que liga as estratégias às formas (estruturais) de atuação e a medidas de desempenho (estas medidas são, necessariamente, associadas aos objetivos). A distinção entre motivações também permite aferir como influenciarão a seleção das próprias localizações.

Este artigo tem duas mensagens distintas. Para investigadores em negócios internacionais, aponta que é necessária uma análise mais abrangente das condicionantes de escolhas - neste caso restrita à escolha dos modos de entrada - específicas. Para os executivos, alerta para a necessidade de ajustar as motivações aos modos de entrada avaliando a viabilidade de estratégias específicas para cada país estrangeiro. Se os objetivos ao operar num determinado mercado são claros, o modo de atingi-los pode ser substancialmente diverso. Certos modos de entrada em mercados externos serão mais adequados a determinado fim, mas deverá sempre ser tido em conta o mercado em que a EMN vai entrar. Não existe, portanto, uma "receita" para qual o melhor modo de entrada nos mercados externos.

A investigação futura pode tomar vários caminhos. Neste artigo não abordamos a perspectiva mais institucional que advoga que as EMNs estão sujeitas a múltiplas pressões para adaptação ao ambiente externo e de conformidade ao ambiente interno. A teoria institucional tem sido encarada como determinística, sendo as organizações a operar num determinado contexto 
Manuel Aníbal Silva Portugal Vasconcelos Ferreira, Fernando Ribeiro Serra \& Nuno Rosa Reis.

institucional, forçadas a adaptar-se a pressões institucionais sofridas (OLIVER, 1991; FERREIRA ET AL., 2009). Contudo, alguns autores (por exemplo, OLIVER, 1991; SUCHMAN, 1995) sugerem que as empresas selecionam a melhor resposta face ao ambiente que enfrentam, desenvolvendo respostas estratégicas a pressões institucionais específicas, conferindo a estas respostas diferentes níveis de legitimidade.

É possível, por exemplo, que pressões internas afetem a capacidade de as EMNs prosseguirem uma estratégia de procura de recursos estratégicos. Estratégias de procura de recursos estratégicos implicam a prospecção de novos recursos (MARCH, 1991; FERREIRA, 2008; FERREIRA; SERRA; REIS, 2011), ao passo que uma estratégia de procura de mercados foca a exploração dos recursos, capabilities e rotinas já detidos pelas empresas (NELSON; WINTER, 1982; BARNEY, 1991; TEECE; PISANO; SHUEN, 1997; TRIPSAS, 1997; FERREIRA; ET AL., 2011). Assim, estratégias de procura de mercados devem cumprir normas e procedimentos internos para explorar as vantagens de posse (DUNNING, 1977, 1998) nos mercados externos. Assim, importa entender o impacto destas questões na seleção dos modos de entrada e, eventualmente, nas localizações.

Ao integrar três dimensões (motivações, modos de entrada e localizações) não conceptualizamos um modelo exaustivo. Vários outros fatores devem ser considerados, como os específicos a uma dada indústria que podem influenciar quer as motivações, quer os próprios modos de entrada e até as localizações que são escolhidas. É o caso de indústrias que exijam grandes investimentos em ativos específicos no país anfitrião: nestas situações, as EMNs preferirão deter a posse das operações, através de operações de greenfield wholly owned ou aquisições (SCHERER; ROSS, 1990; PUCK; HOLTBRUGGE; MOHR, 2009).

Concluindo, ao implementar estratégias de procura de mercados ou de procura de recursos estratégicos em determinado mercado é essencial ter em atenção as idiossincrasias do mercado anfitrião e das operações das EMNs.

Revista Ibero-Americana de Estratégia - RIAE, São Paulo, v. 10, n. 1, p. 29-54, jan/abr. 2011. 
Motivações para a Internacionalização e Modos de Entrada nos Mercados Externos

\section{REFERÊNCIAS}

Agarwal, S.; Ramaswami, S. Choice of foreign market entry mode: Impact of ownership, location, and internalization factors. Journal of International Business Studies, v. 23, n.1, p. 1-27, 1992. http://dx.doi.org/10.1057/palgrave.jibs.8490257

Augier, M.; Teece, D. Dynamic capabilities and multinational enterprise: Penrosean insights and omissions. Management International Review, v. 47, n. 2, p. 175-192, 2007.

http://dx.doi.org/10.1007/s11575-007-0010-8

Barkema, H.; Bell, J.; Pennings, J. Foreign entry, cultural barriers, and learning. Strategic Management Journal, v. 17, n. 2, p. 151-166, 1996.

http://dx.doi.org/10.1002/(SICI)1097-0266(199602)17:2<151::AID-SMJ799>3.3.CO;2-Q

http://dx.doi.org/10.1002/(SICI)1097-0266(199602)17:2<151::AID-SMJ799>3.0.CO;2-Z

Barkema, H.; Vermeulen, F. International expansion through start-up or acquisition: A learning perspective. Academy of Management Journal, v. 41, n. 1, p. 7-26, 1998.

http://dx.doi.org/10.2307/256894

Barney, J. Firm resources and sustained competitive advantage, Journal of Management, v. 17, n. 1, p. 99-120, 1991.

http://dx.doi.org/10.1177/014920639101700108

Beamish, P. The characteristics of joint venture in developed and developing countries. Columbia Journal of World Business, v. 20, n. 3, p. 13-19, 1985

Brouthers, K.; Hennart, J-F. Boundaries of the firm: Insights from international entry mode research. Journal of Management, v.33, n.3, p. 395-425, 2007.

http://dx.doi.org/10.1177/0149206307300817

Buckley, P.; Cross, A.; Tan, H.; Xin, L.; Voss, H. Historic and emergent trends in chinese outward direct investment. Management International Review, v. 48, n. 6, p. 715-748, 2008.

http://dx.doi.org/10.1007/s11575-008-0104-y

Camison, C.; Fores, B. Knowledge creation and absorptive capacity: The effect of intra-district shared competences. Scandinavian Journal of Management, v. 27, n. 1, p. 66-86, 2011. http://dx.doi.org/10.1016/j.scaman.2010.11.006

Cantwell, J. Innovation and information technology in MNE. In RUGMAN, A. \& BREWER, T. (Eds.). Oxford Handbook of International Business. Oxford: Oxford University Press, 2001. http://dx.doi.org/10.1093/0199241821.003.0016

Cantwell, J. Technological innovations and multinational corporations. Oxford: Blackwell, 1989.

Revista Ibero-Americana de Estratégia - RIAE, São Paulo, v. 10, n. 1, p. 29-54, jan/abr. 2011. 
Manuel Aníbal Silva Portugal Vasconcelos Ferreira, Fernando Ribeiro Serra \& Nuno Rosa Reis.

Caves, R. International Corporations: The Industrial Economics of Foreign Investment. Economica, v. 38, n. 149, p. 1-27, 1971.

http://dx.doi.org/10.2307/2551748

Conner, K.; Prahalad, C. A resource-based theory of the firm: Knowledge versus opportunism. Organization Science, v. 7, n. 5, p. 477-501, 1996.

http://dx.doi.org/10.1287/orsc.7.5.477

Cuervo-Cazurra, A.; Genc, M. Transforming disadvantages into advantages: developing-country MNEs in the least developed countries. Journal of International Business Studies, v. 39, n. 6, p. 957-979, 2008.

http://dx.doi.org/10.1057/palgrave.jibs.8400390

Demirbag, M.; Tatoglu, E.; Glaister, K. Factors affecting perceptions of the choice between acquisition and greenfield entry: The case of Western FDI in an emerging market. Management International Review, v. 48, n. 1, p. 5-38, 2008.

http://dx.doi.org/10.1007/s11575-008-0002-3

Deng, P. Investing for strategic resources and its rationale: The case of outward FDI from Chinese companies, Business Horizons, v. 50, n. 1, p. 71-81, 2007.

http://dx.doi.org/10.1016/j.bushor.2006.07.001

Dunning, J. Location and the multinational enterprise: A neglected factor?. Journal of International Business Studies, v. 29, n. 1, p. 45-66, 1998.

http://dx.doi.org/10.1057/palgrave.jibs.8490024

Dunning, J. Multinational enterprises and the global economy. Reading: Addison-Wesley, 1993.

Dunning, J. The Eclectic (OLI) Paradigm of International Production: Past, Present and Future, Int. J. of the Economics of Business, v. 8 n. 2, p. 173-190, 2001.

http://dx.doi.org/10.1080/13571510110051441

Dunning, J. The eclectic paradigm of international production: A restatement and some possible extensions. Journal of International Business Studies, v. 19, n. 1, p. 1-31, 1988.

http://dx.doi.org/10.1057/palgrave.jibs.8490372

Dunning, J. The location of economic activity and the multinational enterprise: A search for an eclectic approach. In OHLIN, B., HESSELBORN, P. and WILKMAN, P. (Eds) The international allocation of economic activity. London: Macmillan, 1977.

Eckel, C. Fragmentation, efficiency seeking FDI and employment. Review of International Economics, v. 11, n. 2, p. 317-331, 2003.

http://dx.doi.org/10.1111/1467-9396.00385

Revista Ibero-Americana de Estratégia - RIAE, São Paulo, v. 10, n. 1, p. 29-54, jan/abr. 2011. 
Motivações para a Internacionalização e Modos de Entrada nos Mercados Externos

Ekholm, K.; Forslid, R.; Markusen, J. Export-platform foreign direct investment. Journal of the European Economic Association, v. 5, n. 4, p. 776-795, 2007.

http://dx.doi.org/10.1162/JEEA.2007.5.4.776

Elango, B. Minimizing effects of 'liability of foreignness': Response strategies of foreign firms in the United States. Journal of World Business, v. 44, n. 1, p. 51-62, 2009.

http://dx.doi.org/10.1016/j.jwb.2008.03.012

Ferreira, M. P.; Serra, F. Foreign entry modes under institutional pressures: The impact of strategic resource seeking and market seeking strategies. Revista de Ciências da Administração, v. 10, n. 22, p. 11-29, 2008.

Ferreira, M. P.; Serra, F.; Li, D.; Armagan, S. Adaptation to the international business environment: A resource advantage perspective. Revista Contemporânea de Contabilidade, v. 1, n. 1, p. 11-29, 2008.

Ferreira, M. The effect of the MNC's capabilities and knowledge strategy on the degree of equity ownership acquired. 2005 Unpublished doctoral dissertation, The University of Utah, USA, 2005.

Ferreira, M.P. Building and leveraging knowledge capabilities through cross-border acquisitions. In TALLMAN, S. (Ed.) A new generation in international strategic management. Northampton: Edward Elgar, 2008.

Ferreira, M.P.; Li, D.; Jang, Y. Foreign entry strategies: Strategic adaptation to the various facets of the institutional environments. Development and Society, v. 38, n. 1, p. 27-55, 2009.

Ferreira, M.P.; Li, S.; Lopes, M.; Serra, F. Cross-border acquisitions of foreign firms in Portugal and of Portuguese firms abroad: Exploration and exploitation through acquisitions. Economia Global e Gestão, v. 12, n. 1, p. 125-147, 2007.

Ferreira, M.P.; Serra, F. Make or buy in a mature industry? Models of client-supplier under TCT and RBV perspectives. BAR - Brazilian Administration Review, v. 7, n. 1, p. 22-39, 2010.

Ferreira, M.P.; Serra, F.; Reis, N. On the adaptation of the firm's strategies to the International Business Environment: A knowledge-based and evolutionary perspective. European Journal of International Management, forthcoming, 2011.

Franco, C.; Rentocchini, F.; Marzetti, G. Why do firms invest abroad? An analysis of the motives underlying foreign direct investments, Trento: Università Degli Studi di Trento, 2008. Discussion paper n.17.

Fujita, M.; Krugman, P.; Venables, A. The spatial economy: Cities, regions, and international trade. Cambridge: MIT Press, 2001.

Revista Ibero-Americana de Estratégia - RIAE, São Paulo, v. 10, n. 1, p. 29-54, jan/abr. 2011. 
Manuel Aníbal Silva Portugal Vasconcelos Ferreira, Fernando Ribeiro Serra \& Nuno Rosa Reis.

Gao, G.; Pan, Y. The pace of MNEs' sequential entries: Cumulative entry experience and the dynamic process. Journal of International Business Studies, v. 41, n. 9, p. 1572-1580, 2010. http://dx.doi.org/10.1057/jibs.2010.15

Gupta, O.; Ross, G. Mergers and acquisitions through an intellectual capital perspective, Journal of Intellectual Capital, v. 2, n. 3, p. 297-309, 2001. http://dx.doi.org/10.1108/14691930110400092

Head, K.; Ries, J.; Swenson, D. Agglomeration benefits and location choice: Evidence from japanese manufacturing investments in the United States. Journal of International Economics, v. 38, n. 3-4, p. 223-247, 1995.

http://dx.doi.org/10.1016/0022-1996(94)01351-R

Hennart, J-F. A theory of the multinational enterprise. Ann Arbor: University of Michigan Press, 1982.

Hill, C.; Hwang, P.; Kim, C. An eclectic theory of the choice of international entry mode, Strategic Management Journal, v. 11, n. 2, p. 117-128, 1990.

http://dx.doi.org/10.1002/smj.4250110204

Hymer, S. The international operations of national firms: A study of direct foreign investment. Cambridge: MIT Press, 1976.

Johanson, J.; Mattsson, L-G. Internationalization in industrial systems: A network approach. In HOOD, N.; VAHLNE, J-E. (Eds.) Strategies in Global Competition. New York: Croom Helm, 1988.

Johanson, J.; Vahlne, J.-E. The Uppsala internationalization process model revisited: From liability of foreignness to liability of outsidership. Journal of International Business Studies, v. 40, n. 9, p. 1411-1431, 2009.

http://dx.doi.org/10.1057/jibs.2009.24

Li, D.; Ferreira, M.P.; Serra, F. Technology transfer within MNEs: Inter-subsidiary competition and cooperation. Revista de Administração e Inovação, v. 6, n. 1, p. 139-158, 2009.

LuostarineN, R.; Welch, L. International business operations. Finland, Helsinki School of Economics, 1990.

Makino, S.; Lau, C.; Yeh, R. Asset-exploitation versus asset-seeking: Implications for location choice of foreign direct investment from Newly Industrialized Economies, Journal of International Business Studies, v. 33, n. 3, p. 403-421, 2002.

http://dx.doi.org/10.1057/palgrave.jibs.8491024

Revista Ibero-Americana de Estratégia - RIAE, São Paulo, v. 10, n. 1, p. 29-54, jan/abr. 2011. 
Motivações para a Internacionalização e Modos de Entrada nos Mercados Externos

Makino, S.; Neupert, K. National culture, transaction costs, and the choice between joint venture and wholly owned subsidiary. Journal of International Business Studies, v. 31, n.4, p. 705-713, 2000.

http://dx.doi.org/10.1057/palgrave.jibs.8490930

March, J. Exploration and exploitation in organizational learning. Organization Science, v. 2, n. 1, p. 71-87, 1991.

http://dx.doi.org/10.1287/orsc.2.1.71

Markusen, A. Sticky places in slippery space: A typology of industrial districts. Economic Geography, v. 72, n. 3, p. 293-313, 1996.

http://dx.doi.org/10.2307/144402

Markusen, J.; Venables, A. Multinational firms and the new trade theory. Journal of International Economics, v. 46, n. 2, p. 183-203, 1998.

http://dx.doi.org/10.1016/S0022-1996(97)00052-4

Markusen, J.; Venables, A. The theory of endowment, intra-industry and multinational trade. Journal of International Economics, v. 52, n. 2, p. 209-234, 2000.

http://dx.doi.org/10.1016/S0022-1996(99)00055-0

Marshall, A. Principles of economics. London: Macmillan, 1920.

Maskell, P. Towards a knowledge-based theory of the geographical cluster. Industrial and Corporate Change, v. 10, n. 4, p. 921-943, 2001.

http://dx.doi.org/10.1093/icc/10.4.921

Morschett, D.; Schramm-Klein, H.; Swoboda, B. Decades of research on market entry modes: What do we really know about external antecedents of entry mode choice?. Journal of International Management, v. 16, n. 1, p. 60-77, 2010.

http://dx.doi.org/10.1016/j.intman.2009.09.002

Nachum, L.; Zaheer, S. The persistence of distance? The impact of technology on MNE motivations for foreign investment. Strategic Management Journal, v. 26, n. 8, p. 747-767, 2005.

$\underline{\text { http://dx.doi.org/10.1002/smj.472 }}$

Narula, R.; Marin, A. Exploring the relationship between direct and indirect spillovers from FDI in Argentina. Maastricht: MERIT, 2005. MERIT Research Memoranda 2005-024.

Nelson, R.; Winter, S. An evolutionary theory of economic change. Cambridge: Belknap/Harvard, 1982. 
Manuel Aníbal Silva Portugal Vasconcelos Ferreira, Fernando Ribeiro Serra \& Nuno Rosa Reis.

Nielsen, B.; Nielsen, S. The role of top management team international orientation in international strategic decision-making: The choice of foreign entry mode. Journal of World Business, v. 46, n. 2, p. 185-193, 2011.

http://dx.doi.org/10.1016/j.jwb.2010.05.003

Oliver, C. Strategic responses to institutional processes. Academy of Management Review, v. 16, n. 1, p. 145-179, 1991.

http://dx.doi.org/10.2307/258610

http://dx.doi.org/10.5465/AMR.1991.4279002

Ping, D. Why do Chinese firms tend to acquire strategic assets in international expansion?. Journal of World Business, v. 44, n. 1, p. 74-84, 2009.

http://dx.doi.org/10.1016/j.jwb.2008.03.014

Porter, M. Location, competition and economic development: Local clusters in a global economy. Economic Development Quarterly, v. 14, n. 1, p. 15-34, 2000.

http://dx.doi.org/10.1177/089124240001400105

Porter, M. The competitive advantage of nations. New York: Free Press, 1990.

Pradhan, J.; Abraham, V. Overseas mergers and acquisitions by Indian enterprises: Patterns and motivations, Indian Journal of Economics, v. LXXXV, n. 33, p. 365-386, 2005.

Puck, J.; Holtbrugge, D.; Mohr, A. Beyond entry mode choice: Explaining the conversion of joint ventures into wholly owned subsidiaries in the People's Republic of China. Journal of International Business Studies, v. 40, n. 3, p. 388-404, 2009.

http://dx.doi.org/10.1057/jibs.2008.56

Root, F. Entry strategies for international markets. Lexington: Lexington Books, 1994.

Rugman, A. Inside the multinationals: The economics of internal markets. London: Croom Helm, 1981.

Scherer, F.; Ross, D. Industrial market structure and economic performance. Boston: Houghton and Mifflin, 1990.

Suchman, M. Managing legitimacy: Strategic and institutional approaches. Academy of Management Review, v. 20, n. 3, p. 517-610, 1995. http://dx.doi.org/10.5465/AMR.1995.9508080331 http://dx.doi.org/10.2307/258788

Tallman, S.; Fladmoe-Lindquist, K. Internationalization, globalization, and capability-based strategy. California Management Review, v. 45, n. 1, p. 116-135, 2002.

Revista Ibero-Americana de Estratégia - RIAE, São Paulo, v. 10, n. 1, p. 29-54, jan/abr. 2011. 
Motivações para a Internacionalização e Modos de Entrada nos Mercados Externos

Tallman, S.; Jenkins, M., Henry, N.; Pinch, S. Knowledge Clusters and Competitive Advantage, Academy of Management Review, v. 29, n. 2, p. 258-271, 2004.

http://dx.doi.org/10.5465/AMR.2004.12736089

http://dx.doi.org/10.2307/20159032

Teece, D.; Pisano, G.; Shuen, A. Dynamic capabilities and strategic management. Strategic Management Journal, v. 18, n. 7, p. 509-533, 1997.

http://dx.doi.org/10.1002/(SICI)1097-0266(199708)18:7<509::AID-SMJ882>3.0.CO;2-Z

Tripsas, M. Unraveling the process of creative destruction: Complementary assets and incumbent survival in the typesetter industry. Strategic Management Journal, v. 18, special issue, p. 119$142,1997$.

http://dx.doi.org/10.1002/(SICI)1097-0266(199707)18:1+<119::AID-SMJ921>3.3.CO;2-S

Williamson, O. The economic institutions of capitalism: Firms, markets, relational contracting. New York, Free Press, 1985.

Zaheer, S. Overcoming the liability of foreignness. Academy of Management Journal, v. 38, n. 2, p. 341-363, 1995.

http://dx.doi.org/10.2307/256683

Zander, U.; Kogut, B. Knowledge and the speed of the transfer and imitation of organizational capabilities: An empirical test. Organization Science, v. 6, n. 1, p. 76-92, 1995.

http://dx.doi.org/10.1287/orsc.6.1.76

Zanfei, A. Transnational firms and changing organization of innovative activities. Cambridge Journal of Economics, v. 24, n. 5, p. 515-554, 2000.

http://dx.doi.org/10.1093/cje/24.5.515

Recebido: 15/12/2010

Aprovado: 25/02/2011

Revista Ibero-Americana de Estratégia - RIAE, São Paulo, v. 10, n. 1, p. 29-54, jan/abr. 2011. 